\title{
Artigos
}

\section{O PAPEL PEDAGÓGICO DA EXTENSÃO UNIVERSITÁRIA}

Geraldo Ceni Coelho ${ }^{1}$

RESUMO: A extensão universitária, muito recentemente, tornou-se uma terceira missão formalmente reconhecida nas universidades. De uma atividade unidirecional destinada à difusão do conhecimento acadêmico à comunidade extramuros e à prestação de serviços, a extensão passou a ser entendida como uma interação dialógica com a sociedade. Como consequência, uma dimensão pedagógica tem sido atribuída à extensão universitária. Como instrumento de aprendizagem e geração de conhecimentos, a extensão pode contribuir para o desenvolvimento de seus estudantes e profissionais. Este artigo tem como objetivo apresentar o conceito de extensão universitária e suas mais importantes modificações ao longo da história, identificando o surgimento da prática da extensão universitária como instrumento pedagógico. A partir daí, trata de discutir o potencial da atividade extensionista na qualificação da trajetória formativa dos estudantes universitários. São apresentados trabalhos de investigação sobre o tema do impacto pedagógico da extensão universitária, buscando-se discutir a contribuição dessa atividade para qualificar a universidade e seus egressos. Os trabalhos publicados mostram que a extensão universitária pode influenciar significativamente a formação universitária, em especial nos aspectos cívico-políticos e afetivo-comportamentais.

PALAVRAS-CHAVE: Atividade extramuros. Extensão universitária. Impacto pedagógico.

\section{The pedagogic role of university extension}

ABSTRACT: More recently, the university extension became a third mission formally recognized in the universities. First, university extension was seen as a unidirectional activity devoted to the dissemination of academic knowledge to the extramural community and to service practices. Now, extension came to be understood as a dialogic interaction with society. As a result, an educational dimension has been attributed to the university extension. As a tool for learning and knowledge creation, the extension may contribute to the development of their students and professionals. This article aims to introduce the concept of university extension and its most significant changes throughout history, identifying the emergence of the practice of university extension as a pedagogical tool. From this, it discusses the possibilities of extension insertion in qualifying formative trajectory of university students. Investigation papers about the pedagogical impact of university extension are presented seeking to discuss the contribution of this activity to qualify university and its graduates. Published papers show that university extension can significantly influence university education, particularly in the civic-political, affective and behavioral aspects.

KEYWORDS: Extramural activities. University extension. Pedagogical impact.

\footnotetext{
${ }^{1}$ Doutor em Ciências Farmacêuticas (Fitoquímica) pela Universidade Federal do Rio Grande do Sul, professor adjunto da Universidade Federal de Fronteira do Sul (cenicoelho@gmail.com).
} 


\section{INTRODUÇÃO}

A Universidade passou por diversas e profundas transformações ao longo de seus mais de 1.000 anos de história. Até o século 19, entretanto, sua atividade se dava em torno da dimensão que, contemporaneamente, é denominada ensino. A pesquisa não era formalmente reconhecida, e apenas esporadicamente se tem registro de atividades de investigação e geração de conhecimentos nesse primeiro período. A dimensão de serviços à sociedade se restringia a consultorias e aconselhamentos prestados a monarcas e aos altos dirigentes religiosos (SCOTT, 2006). Na primeira metade do século 19, John Henry Newman (18011890) afirmou ser a Universidade um "lugar em que se ensina conhecimento universal [...] se trata antes da difusão e propagação do conhecimento do que de seu avanço". Para ele, se o objeto da universidade fosse a descoberta científica e filosófica, não haveria porque ter estudantes. Newman não ignorava a proposta de associação íntima entre pesquisa e ensino no seio universitário, proferida por seu contemporâneo, Wilhelm Von Humboldt (1767-1835), mas, antes, se opunha à sua influência, que já se propagava entre as universidades do Reino Unido naquele período (SEIFERT, 2002).

A partir da proposta Humboldtiana, temos o avanço científico e a produção de novos conhecimentos como uma nova e estruturante missão da Universidade (GERHARDT, 2002). Esse novo conceito, que a situava como lugar de produção de conhecimento, não tardou a se difundir no Reino Unido e nos Estados Unidos (CUMMINGS, 1998). Durante o século 20, a atividade investigativa ocupou um lugar cada vez mais amplo na estruturação das universidades e se difundiu em nível global.

Ainda no século 19, a extensão universitária somou-se ao ensino e à pesquisa para se constituir formalmente como a terceira dimensão das instituições de ensino superior. O início das atividades extensionistas nas instituições universitárias é impreciso e matéria de controvérsia (SOUSA, 2010). Possivelmente, a extensão universitária foi formalizada pela primeira vez dentro das chamadas "Land Grant Universities", universidades constituídas pelos estados da federação estadunidense em terras concedidas pelo governo federal dos Estados Unidos.

A criação de tais instituições teve como marco legal o "Morris Act", de 1862, no qual um de seus princípios fundamentais expressava que nenhuma parte da vida ou trabalho humano estava em posição inferior ao escopo da Universidade ou não possuía sua própria dignidade. "Por meio do caráter de sua educação e, considerando para quem a Universidade serve, as universidades de concessão de terras foram estabelecidas como universidades populares" (MCDOWELL, 2003, p. 33), incluindo em seu alunado pessoas cuja experiência prévia se dava em padarias, campos agrícolas, indústrias, deixando de ser apenas reservada à aristocracia.

Inicialmente, a extensão nessas universidades se caracterizou pela realização de investigação sobre temas de demanda e aplicação direta na indústria e comércio. Com os avanços na pesquisa em agricultura, os trabalhos de extensão se intensificaram nas comunidades rurais, especialmente na forma de cursos e difusão do conhecimento. A Universidade de Wisconsin (EUA) iniciou seus trabalhos extensionistas em 1880, destinando cursos sobre tópicos agrícolas a trabalhadores rurais (ZIEREN; STODDARD, 2004). No início do século 20, foi criado o serviço cooperativo de extensão - Cooperative Extension - formalizado, legalmente, a partir de 1914 (MCDOWELL, 2003).

A partir de 1912, a Universidade Livre de São Paulo buscou adaptar a experiência das Universidades Populares da Europa, oferecendo cursos e conferências gratuitos abertos à 
população interessada. Já a Escola Superior de Agricultura e Veterinária de Viçosa, criada em 1926, se espelhou nas "Land Grant Universities" e sua extensão com ênfase em serviços e difusão de conhecimentos. Essas duas instituições brasileiras podem ser consideradas experiências pioneiras em extensão no Brasil. Contudo, o termo extensão universitária só será referido na legislação brasileira a partir do Decreto-Lei 19.851, de 1931, denominado de Estatuto das Universidades Brasileiras (SOUSA, 2010). Outras manifestações em prol da extensão universitária e abertura da Universidade aos problemas da sociedade ocorreram aqui e ali pela América Latina, com poucas repercussões práticas. Cumpre destacar o Manifesto de Córdoba, que, em boa parte, é fruto da iniciativa estudantil, e que sinaliza uma agenda para a reforma universitária, incluindo "extensão universitária, fortalecimento da função social da universidade, projeção ao povo da cultura universitária e atenção aos problemas nacionais" (GUTIÉRREZ, 1992, p. 3).

Até os anos de 1980, não só no Brasil, como em outros países, a extensão universitária apresentou pouco ou mesmo nenhum crescimento, embora, eventualmente, surgissem manifestações em sua defesa muitas vezes por parte dos estudantes universitários (SOUSA, 2010). Podemos caracterizar essa fase como um período de dormência. A retomada de sua importância aconteceu na década de 1980 e adveio, em boa parte, da crise universitária em seus aspectos de financiamento, que passa a decair em diversos países, e de uma crise de legitimidade, caracterizada pelo questionamento ao isolamento academicista (LYNTON, 1983; ROPER; HIRTH, 2005; SOUZA SANTOS, 2010). A extensão passa a ser, portanto, uma estratégia de buscar ou justificar maiores investimentos e, ao mesmo tempo, promover uma legitimação do saber acadêmico na direção das demandas sociais, tornando-o mais aplicado e buscando sua validação em situações mais tangíveis.

De modo sintético, a revalorização e o consequente crescimento da extensão como atividade universitária, nos últimos 40 anos, teve como principais motivações:

a) Para os professores, a procura de romper o isolamento da Universidade, e aumentar o seu prestígio e a sua influência na sociedade;

b) Para os estudantes, pelas mesmas razões, e por reivindicar experiências práticas que pudessem contribuir para sua formação profissional;

c) Para a comunidade, por buscar na Universidade conhecimentos úteis que pudessem contribuir para o esclarecimento e a solução de problemas;

d) Para o Estado, por ver na Universidade a possibilidade de promover políticas sociais e qualificação de diferentes setores, em diversas áreas e níveis.

O presente artigo pretende apresentar algumas das principais modificações históricas quanto ao conceito da extensão universitária, identificando as bases teóricas para sua inserção enquanto atividade formativa, de cunho pedagógico, na vida universitária. A seguir, será apresentada uma síntese de publicações que relatam investigações sobre o impacto da atividade extensionista na qualificação da formação universitária. Para isso, foram selecionados trabalhos que apresentam avaliações qualitativas ou quantitativas sobre os impactos da participação em atividades de extensão na vida acadêmica e na formação dos estudantes de nível superior. Ao final, são discutidos as categorias ou parâmetros de avaliação dos impactos da extensão universitária apresentados nesses estudos, bem como suas possibilidades e limites metodológicos.

O conceito de extensão universitária não é livre de ambiguidades, por isso, para a presente discussão, pressupõe-se um conceito amplo: atividades que a comunidade universitária realiza com a comunidade externa (por isso também chamada atividade extramuros), que podem 
incluir uma série de ações, tais como cursos, assistência técnica, formação continuada a profissionais diversos e prestação de serviços.

\section{Mudanças conceituais recentes e a emergência da dimensão pedagógica da extensão universitária}

\section{Extensão e formação: aspectos conceituais}

Inicialmente concebida no Brasil como uma atividade destinada à "difusão dos conhecimentos úteis, à ajuda individual ou coletiva, à solução de problemas sociais ou à propagação de ideias e princípios" (BRASIL, 1931, p. 8), a extensão universitária brasileira se inspirou nas experiências universitárias estadunidenses anteriormente referidas, ou mesmo nas iniciativas universitárias europeias, em especial na Inglaterra do último terço do século 19 (DE PAULA, 2013), enfatizando seu caráter de divulgação e difusão de conhecimentos acadêmicos (SOUSA, 2010).

Mais recentemente, a extensão universitária experimentou mudanças conceituais importantes, especialmente a partir de 1970. Já em 1972, no México, durante a Segunda Conferência Latinoamericana de Extensão Universitária e Difusão Cultural, se expressou que extensão universitária é "a interação entre Universidade e os demais componentes do corpo social, por meio do qual esta assume e cumpre seu compromisso de participação no processo social de criação da cultura e de libertação e transformação radical da comunidade nacional" (GUTIÉRREZ, 1992, p. 5, grifos nossos).

De forma precursora, Freire, em 1969, expôs uma crítica à prática extensionista difusionista tradicional, considerando que:

$$
\begin{aligned}
& \text { nem aos camponeses, nem a ninguém, se persuade ou se submete à força } \\
& \text { mítica da propaganda, quando se tem uma opção libertadora. [...] aos } \\
& \text { homens se lhes problematiza sua situação concreta, objetiva, real, para que, } \\
& \text { captando-a criticamente, atuem, também criticamente, sobre ela. [...] educar } \\
& \text { e educar-se, na prática da liberdade, é tarefa daqueles que sabem que pouco } \\
& \text { sabem - por isso sabem que sabem algo e podem assim chegar a saber mais } \\
& \text { - em diálogo com aqueles que, quase sempre, pensam que nada sabem, para } \\
& \text { que estes, transformando seu pensar que nada sabem em saber que pouco } \\
& \text { sabem, possam igualmente saber mais. (FREIRE, 1977, p. 14, grifos nossos). }
\end{aligned}
$$

Tal conceito de prática dialógica foi tomado como novo paradigma pedagógico da extensão, especialmente no Brasil e em outros países latinoamericanos. Possivelmente, a primeira expressão teórica desse novo paradigma da extensão tenha vindo das publicações pioneiras do FORPROEX (Fórum Nacional dos Pró-reitores de Extensão das Universidades Públicas Brasileiras), que promoveu, na década de 1980, discussões que resultaram em referências teóricas importantes, no Brasil, e que foram incorporadas à legislação. Em seu primeiro encontro nacional, realizado na Universidade de Brasília (UnB), em Brasília, o FORPROEX afirmou que:

A Extensão Universitária é o processo educativo, cultural e científico que articula o Ensino e a Pesquisa de forma indissociável e viabiliza a relação transformadora entre Universidade e Sociedade. [...] é uma via de mãodupla, com trânsito assegurado à comunidade acadêmica, que encontrará, na sociedade, a oportunidade de elaboração da práxis de um conhecimento 
acadêmico. No retorno à Universidade, docentes e discentes trarão um aprendizado que, submetido à reflexão teórica, será acrescido àquele conhecimento. (FORPROEX, 1987, p. 11, grifos nossos).

Essa mudança conceitual, que introduz o conceito de extensão universitária como relação transformadora e via de mão-dupla em que os discentes e docentes adquirem aprendizado, foi incorporada literalmente à Lei Nacional de Diretrizes e Bases da Educação (BRASIL, 1996), e é fundamental para entender a extensão como instrumento pedagógico, cuja função não é transmitir, unidirecionalmente, o conhecimento da universidade para o público externo. Assim, tanto o discente quanto o docente podem aprender (função típica do ensino). Com crescente ênfase, admite-se que a experiência extensionista é fonte de aprendizado não só para estudantes (ROGERS et al., 2001), mas também para docentes universitários, que têm oportunidade de por à prova seus conhecimentos e aperfeiçoá-los.

Nos Estados Unidos, nas décadas de 1970 e 1980, também surgiram questionamentos quanto ao isolamento da Universidade em relação à sociedade e a necessidade de uma interação mais intensa com a comunidade extramuros. Lynton (1983) propõe uma perspectiva nova para o ensino universitário, em que a Universidade deixe de ser uma instituição

isolada e apartada, existindo em uma sociedade estática, imune a mudanças devido ao grande intervalo entre novas ideias e suas aplicações [...]. Devemos, de modo consciente, desenvolver uma interação muito mais simbiótica com o mundo à nossa volta. Isto requer um fluxo bidirecional de comunicação com uma vasta gama de sujeitos, levando a um compartilhamento de responsabilidades para decisões em muitas áreas as quais, até o momento, nós somente analisamos a partir de nosso próprio domínio. (LYNTON, 1983, p. 53, grifos nossos).

Ressalta-se, porém, que a extensão universitária segue sendo praticada sob diferentes conceitos e formatos (GUTIÉRREZ, 1992), e "a via de mão-dupla" é uma característica que se manifesta em graus variados, ou podendo mesmo estar ausente.

\section{A extensão como instrumento pedagógico}

O reconhecimento da extensão como instrumento pedagógico na formação universitária e a consequente formalização da extensão na estrutura curricular são processos relativamente recentes que, grosso modo, passam a acontecer a partir dos anos de 1980. Não obstante, alguns indicativos teóricos, nesse sentido, são apontados em autores mais antigos. A sugestão de John Dewey - de que ações voltadas à promoção do bem-estar de outros promovem o desenvolvimento acadêmico e social - e a proposição de William H. Killpatrick - que cunhou o termo "método por projetos", sugerindo que o aprendizado deveria ocorrer fora da escola, envolvendo esforços para atender às reais necessidades da comunidade - são consideradas precursoras do conceito (SIMPSON, 1998).

Em geral, a extensão é entendida como um instrumento pedagógico complementar ou acessório (GUTIÉRREZ, 1992) e, portanto, opcional. Porém, cresce a tese de que a extensão universitária é essencial para promover uma educação de qualidade. O processo educacional proposto nas universidades, além de formar um profissional com conhecimentos técnicos, deve oportunizar ao aluno a "aprender a conhecer, aprender a fazer, aprender a conviver e aprender a ser. Sem isso, o ensino tradicional, centrado no aprendizado e na transmissão exclusiva do conhecimento do professor não contemplará a integralidade da formação" (PONTE et al., 2009, p. 530). 
Em sua dimensão pedagógica [a extensão] constitui uma metodologia de aprendizagem integral e humanizadora. A extensão e a investigação deveriam ser parte da metodologia de ensino universitário, o que faria com que o processo formativo fosse integral, com um contato direto com a realidade social. (UDELAR, 2010, grifo nosso).

A participação da extensão, como atividade formadora, desloca o eixo pedagógico clássico professor-aluno para o eixo aluno-comunidade, com a atuação do professor como coparticipante, orientador, educador, tutor e pedagogo (CORRÊA, 2003).

A participação em atividades extensionistas permite aos estudantes, por um lado, aumentar seu engajamento social e desenvolver cidadania e, por outro, qualificar-se profissionalmente, tendo, na interação com a sociedade, fonte de conhecimentos e desenvolvimento de habilidades, sentindo-se, dessa forma, mais seguros para o exercício profissional após a diplomação.

Certas habilidades adquiridas na extensão não são usualmente assimiladas na experiência do ensino formal (por meio de disciplinas), tais como: capacidade de interagir e organizar o trabalho em equipes (especialmente as multidisciplinares); saber ouvir e saber comunicar diante de públicos diversos e diferentes daqueles que circulam no meio acadêmico (DEGREAS; KATAKURA, 2009; MUSCIO, 2011; LAURSEN et al., 2012; MATTHEWS, 2012).

Mesmo dentro do universo dos temas específicos, a experiência extensionista proporciona oportunidade ímpar de contato com a ação profissional (DE CONTO, 2013), além de ampliar ou reforçar a aprendizagem de habilidades que o estudo disciplinar ou mesmo os estágios não contemplam de forma suficiente, na medida em que promove conhecimentos e temas sui generis, em diferentes áreas (DIOGO, 2004).

Pela diversidade de ações que a extensão oferece, ampliando o restrito universo profissional contemplado pelo ensino disciplinar, ela pode, muitas vezes, reforçar o interesse pelo exercício profissional futuro na profissão escolhida ou redirecionar o futuro exercício profissional para papéis antes pouco cogitados ou valorizados (LAURSEN et al., 2012). Fonseca et al. (2000) exemplificam, apontando a educação de jovens e adultos, como uma dessas áreas usualmente pouco ou não contempladas na formação de graduação e pouco valorizadas enquanto escolha profissional, mas que passam a ter mais valor por exparticipantes de trabalhos extensionistas nessa linha temática. A extensão também pode contribuir para a construção de valores sociais, como o desenvolvimento da cidadania e a redução de estereótipos étnicos (GILES; EYLER, 1994).

Na medida em que cresceu a interação com o ensino, a efetividade e a importância da extensão como qualificadora do ensino de graduação e como atividade pedagógica e formativa também passaram a ser objeto de investigação. A pesquisa científica sobre os impactos da extensão pôde contribuir para o aperfeiçoamento teórico e prático nas dimensões do ensino e da extensão e orientar as políticas públicas que a fomentam.

Todavia, em que pese toda a importância recentemente dada à função pedagógica da extensão, são escassos, no Brasil e América Latina, estudos que demonstrem a efetividade da atividade extensionista universitária na qualificação dos estudantes. A literatura brasileira, em especial aquela publicada em periódicos especializados em extensão universitária, concentra-se em questões conceituais e históricas sobre extensão universitária, relatos de experiência sobre atividades de extensão e, mais raramente, impactos sociais ou pedagógicos da atividade extensionista sobre a comunidade externa. São raros os trabalhos que avaliam empiricamente, 
de forma qualitativa ou quantitativa, os impactos da participação dos estudantes nessa modalidade acadêmica, sobre sua própria formação.

Entre os estudos publicados, no Brasil ou em outros países, e dedicados a avaliar as consequências da atividade de extensão universitária na formação acadêmica, a grande maioria se restringe ao impacto da participação em ações extensionistas, sem a preocupação com a comparação em relação aos não participantes (grupos controle). Do ponto de vista epistemológico, tais estudos têm contribuição limitada para embasar inferências sobre a importância de ampliar a presença da extensão na estrutura curricular.

\section{O impacto da extensão universitária na formação}

Apresentamos, aqui, estudos dedicados à análise dos impactos da atividade extensionista no nível superior de formação, selecionados entre aqueles que apresentam abordagens qualitativas ou quantitativas (ou ambas), com especial atenção aos que, como método, compararam estudantes com e sem participação em atividades extensionistas.

Weiler et al. (2013) verificaram, por meio de uma abordagem quantitativa, que os estudantes que participaram de uma atividade de extensão de apoio a jovens em situação de risco, quando comparados com estudantes que não passaram por experiência equivalente, apresentam maior confiança em sua própria capacidade de contribuir para a comunidade, maior autoestima, maior valorização de ações de valor cívico, e maior capacidade de resolver problemas e de solucionar questões de relacionamento interpessoal.

Osborne et al. (1998) verificaram que estudantes de Farmácia participantes de experiências de extensão, comparados a um grupo controle, obtiveram crescimento maior em termos de capacidade cognitiva (habilidade de escrever, relacionar temas e conceitos de forma complexa e descrever em profundidade suas ideias), e perceberam em si próprios um aumento de habilidades em trabalhos sociais e autoconfiança.

Estudantes de Engenharia que participaram de trabalhos de extensão, em comparação com aqueles que participaram de projetos de outra natureza (por exemplo, simulações teóricas), apresentaram não só motivação maior para o estudo e o curso, mas também uma maior autopercepção da capacidade cognitiva, o que inclui habilidade em desenhar sistemas, componentes ou processos, identificar, formular e resolver problemas e utilizar técnicas e ferramentas modernas de engenharia (SEVIER et al., 2012).

Seider et al. (2012) verificaram que estudantes participantes de atividades de extensão, quando comparados a um grupo controle, apresentam uma disposição maior para um engajamento cívico, definido como um conjunto de atitudes que incluem: assumir um papel ativo em processos políticos na vida pública; solucionar problemas públicos; e participar de serviços à comunidade. Muitos participantes revelaram que seu maior engajamento cívico (subproduto da participação extensionsista) derivou do aprofundamento, em sua compreensão, das questões sociais e políticas contemporâneas. Além disso, muitos reportam uma reorientação de seu futuro exercício profissional, em direção a uma atuação com maior significado social.

Evidências de estudos anteriores, sem grupos controle, que abordaram efeitos da participação em ações de extensão, também indicaram aumento de capacidades relacionadas à cidadania, maior importância dada à participação política, responsabilidade social e consciência dos problemas da comunidade (GILES; EYLER, 1994; SIMONS; CLEARY, 2006). 
Em um estudo recente, Santos et al. (2013) relatam a percepção dos estudantes universitários de que a atividade extensionista é uma via de troca de saberes, que se traduz na fala de um dos entrevistados: "por incrível que pareça, se aprende muito mais do que [se] ensina". Os autores destacam, ainda, que a dimensão político-social é também percebida pelos participantes, especialmente no sentido de dar retorno à sociedade, considerando o investimento que ela faz na universidade pública.

Reed et al. (2005) verificaram que mesmo atividades de extensão de curta duração (8-10 horas) são capazes de promover mudanças significativas, de acordo com a declaração dos sujeitos pesquisados (neste caso, alunos de Psicologia em contato com pacientes terminais), em termos de senso de responsabilidade social, valorização de suas atividades acadêmicas, interesse em participar de atividades futuras envolvendo cuidado na área de saúde. Entretanto, verificou-se um aumento no nível de ansiedade relacionada à morte. Embora, a rigor, essa situação de estudo não consiga caracterizar uma ação extensionista, mostra a importância de vivências em situações e com pessoas reais, em um contexto relacionado à profissão, durante a graduação.

Phelps e Dostilio (2008) reportaram que estudantes de estatística que optaram por um trabalho final dedicado a temas de interesse de grupos sociais em uma situação real, ao invés de um trabalho de conclusão teórico, declararam (em uma proporção significativamente maior) que o trabalho desenvolvido tinha relação com o mundo real, poderia beneficiar outras pessoas e contribuir para o desenvolvimento dos próprios estudos. Entretanto, os grupos não diferiram em termos de desempenho nos exames finais e na avaliação obtida no trabalho de conclusão.

Por outro lado, Batchelder e Root (1994) observaram que estudantes que participaram de experiências de extensão, quando comparados a um grupo controle e diante de questões sobre problemas sociais, apresentaram respostas descritivas que revelaram maior capacidade de lidar com questões complexas multidimensionais de natureza social, ou seja, foram capazes de associar múltiplas dimensões relacionadas ao problema (sociais, econômicas, políticas). Além disso, perceberam também que a qualidade do trabalho de orientação, durante a participação no projeto, promoveu diferenças positivas na capacidade adquirida de resolver problemas ou propor soluções. Os autores sugerem que as capacidades adquiridas se aplicaram tanto a questões diretamente ligadas à experiência extensionista quanto a questões gerais relacionadas ao curso, indicando que as habilidades cognitivas desenvolvidas são de caráter geral. Já Romack (2003) registrou um valor mais elevado das notas em avaliações para estudantes que se envolveram em atividades com a comunidade, quando comparados a estudantes que desenvolveram estudos em laboratório, na mesma disciplina e turma.

Vogelgesang e Astin (2000) conduziram um estudo que envolveu mais de 19.000 estudantes de 177 diferentes universidades estadunidenses, buscando comparar três possíveis trajetórias de formação universitária: uma que incluiu experiências extracurriculares voluntárias de extensão com a comunidade; uma segunda, caracterizada por disciplinas que envolviam aprendizado por meio de serviços à comunidade (service learning ou extensão universitária incorporada à grade curricular); e uma terceira sem qualquer envolvimento em atividades com a comunidade. Os autores compararam as autopercepções dos estudantes quanto a desenvolvimento cognitivo (capacidade de escrever, capacidade de pensar de forma crítica); notas obtidas no conjunto de disciplinas cursadas; e autopercepção de sua evolução afetivocomportamental (capacidade de liderança, interesse em participar de atividades dedicadas à comunidade em um futuro próximo) e cívico-políticas (grau de compromisso com a participação em atividades políticas, intenção de estar informado sobre questões políticas, interesse em tornar-se um líder comunitário). Compararam, ainda, a evolução desses grupos de estudantes (cada um deles caracterizado por uma das três trajetórias acima) no período 
entre o início do curso universitário e o último ano. Após correções para evitar o efeito relacionado a diferentes universidades e de interesses e experiências prévios expressos na primeira tomada de dados, os autores verificaram que tanto as atividades comunitárias voluntárias quanto àquelas ligadas a disciplinas promoveram valores superiores para todas as variáveis analisadas. Porém, a participação em atividades vinculadas a disciplinas promoveram valores superiores de certas características cognitivas, em relação à simples participação em atividades voluntárias: capacidade de escrever bem (segundo a própria percepção) e valores médios das notas. Isso indicaria que inserir a extensão nos currículos pode ser uma medida favorável a um maior compromisso com a excelência acadêmica. Entretanto, dado que os cursos de graduação em universidades estadunidenses possuem uma grande proporção de disciplinas eletivas ou opcionais, os autores advertem que pesquisas adicionais devem ser necessárias para esclarecer se a diferença nas notas pode estar relacionada à escolha de diferentes disciplinas por parte dos diferentes grupos. Outra conclusão interessante desse estudo: a participação em atividades comunitárias tem maior efeito sobre estudantes que se declararam, no primeiro ano do curso, indecisos quanto a planos de exercer atividades profissionais vinculadas a serviços comunitários no futuro. Essa observação corrobora a importância de vincular as atividades universitárias à estrutura curricular.

As capacidades adquiridas em aprendizados práticos de extensão universitária, detectadas nos estudos até aqui apresentados, podem ser categorizadas em grupos (Quadro 1). Tal classificação é certamente arbitrária, ocorrendo sobreposição entre as categorias em maior ou menor grau, no entanto, pode ser útil para orientar e avaliar instrumentos de pesquisa.

Quadro 1 - Categorias para a avaliação de impactos de atividades extensionistas como instrumento de aprendizado universitário, de acordo com a literatura.

\begin{tabular}{ll}
\hline Categorias & Itens de avaliação \\
\hline Profissional & $\begin{array}{l}\text { Aquisição de conhecimentos que favorecem o desempenho da } \\
\text { atividade profissional; desenvolvimento de atitudes e e } \\
\text { comportamentos adequados à profissão. }\end{array}$
\end{tabular}

Afetivo-comportamentais

Cívicas e políticas

Cognitivas
Autoconfiança; autoestima; capacidade de relacionamento interpessoal; confiança na sua escolha profissional; autorrealização; valorização da formação, participação em eventos e outras atividades acadêmicas de formação.

Capacidade de participar e interferir em questões da esfera política e social; compreensão sobre essas esferas; empatia;

Aprender a aprender; capacidade de expressão escrita; desenvolvimento da memória, capacidade de articular diferentes dimensões de conhecimento.

Fonte: O autor (2014).

Desafios para a investigação da extensão enquanto instrumento pedagógico

Avaliar impactos sobre a trajetória pessoal, seja de estudantes ou de professores, implica analisar impressões subjetivas. O resultado de tais análises pode facilmente ser distorcido 
pelos instrumentos de avaliação (uso de questionários e sua estrutura, entrevistas, entre outros) ou pelas circunstâncias da avaliação (MLODINOV, 2013). Por exemplo, bolsistas de extensão tenderiam a supervalorizar a própria participação em atividades de extensão e os benefícios que ela promove para o desenvolvimento pessoal; estudantes que tenham tido experiências de extensão universitária podem apresentar uma opinião mais favorável ao engajamento da universidade com questões da comunidade ou ter maior clareza sobre o que é cidadania; estudantes que optam por oportunidade de extensão universitária podem ter um interesse prévio maior em qualificar seus estudos que outros que não buscam oportunidades de relacionamento mais direto com a comunidade (PHELPS; DOSTILIO, 2008).

Por outro lado, experiências e motivações anteriores podem ser causas que favorecem a participação em programas de extensão. Assim, estudantes previamente mais motivados para o engajamento comunitário e ações de cidadania tenderiam a ter mais participação voluntária em ações de extensão e a distorcer os resultados de uma avaliação a posteriori, especialmente quando comparados a um grupo controle sem as mesmas inclinações. Vogelgesang e Astin (2000) verificaram que estudantes com experiências de serviços voluntários à comunidade tinham sido monitores durante o ensino médio; ou estudantes que não expressaram interesses financeiros na escolha da carreira, tinham maior tendência à participação em atividades de extensão. Diferenças de gênero também foram observadas: estudantes do sexo feminino apresentavam maior tendência à participação em atividades universitárias junto à comunidade.

Além disso, quando os estudantes se identificam com a natureza da atividade a ser desenvolvida, o impacto observado pode ser melhor do que quando não há identificação com a natureza do trabalho proposto (MOELY et al., 2008). Siedler et al. (2012) verificaram que a participação em atividades extensionistas contribuiu para uma maior disposição à participação política. Porém, a disposição para atitudes de participação política, prévia à experiência extensionista, mostrou maior influência que a experiência em si.

Tanto em estudos quantitativos como qualitativos, uma dificuldade adicional é a própria definição dos conceitos a serem avaliados. Cidadania, habilidades profissionais, qualificação acadêmica e autoconfiança são conceitos concebidos de forma variável e os resultados observados dependem dos instrumentos utilizados. Além disso, a própria natureza multifacetada da extensão universitária, ou mesmo divergências quanto ao que ela seja, representam dificuldades adicionais (LICHTENSTEIN et al., 2011).

Muitos trabalhos avaliam o impacto das atividades de extensão sobre os estudantes, mas poucos apresentam comparações entre antes e depois da participação ou comparações entre sujeitos que participaram e outros que não. Embora todas as modalidades de estudo tenham risco de distorções metodológicas, as comparações com grupos testemunhas são importantes para uma avaliação mais compreensiva do real papel da extensão na formação.

\section{CONSIDERAÇÕES FINAIS}

Vivemos em um período de transformação da Universidade, no qual o papel social dessa milenar instituição tem sido objeto de crítica. Uma participação mais ativa e dialógica junto à comunidade extramuros é cada vez mais requerida. Percebe-se, nesse contexto, um crescimento do fomento à extensão universitária, não só para atender às demandas externas, como também para contribuir com a produção de novos conhecimentos e a qualificação do corpo docente e discente. Além disso, a extensão passou a ter uma dimensão pedagógica, em tese, contribuindo também para o aprendizado e a formação dos estudantes universitários. 
Desse modo, como atividade pedagógica, passa a ser um objeto de estudo no campo educacional ou nas ciências sociais, entre outros.

O Brasil é um país precursor em termos conceituais e práticos no campo da extensão universitária. Entretanto, a escassez de pesquisas nacionais sobre o impacto da extensão na formação universitária surpreende. $\mathrm{O}$ aumento da inclusão de jovens nas universidades e um interesse renovado da sociedade nas instituições de ensino superior na busca de apoio para buscar soluções e inovação (e o recíproco interesse por parte da academia nessa interação) poderão contribuir para incrementar as investigações nesse campo. Adicionalmente, novas perspectivas de financiamento, especialmente o público, para as atividades extensionistas também já estão promovendo o interesse investigativo em suas consequências de caráter pedagógico, cultural e social.

Nos estudos revistos no presente artigo, verifica-se uma interferência mais acentuada da extensão universitária sobre variáveis e atitudes cívico-políticas ou afetivo-comportamentais. Desempenhos ou ganhos cognitivos têm sido pouco estudados e os poucos resultados disponíveis não oferecem um quadro claro. O tema do impacto educacional da atividade extensionista é, portanto, um campo de discussão e investigação que requer mais investimento.

\section{AGRADECIMENTOS}

À Universidade Federal da Fronteira Sul pela oportunidade de desenvolver atividades de extensão universitária. À Profa. Dra. Monica Hass (UFFS), por ter lido e comentado uma versão preliminar deste trabalho.

\section{REFERÊNCIAS}

BATCHELDER, T. H.; ROOT, S. Effects of an undergraduate program to integrate academic learning and service: cognitive, prosocial cognitive, and identity outcomes. Journal of Adolescence, Amsterdan, v. 17, p. 341-355, Aug. 1994.

BRASIL. Estatuto das Universidades Brasileiras. Decreto $\mathrm{n}^{\circ} 19.851$, de 11 de abril de 1931. Rio de Janeiro, 1931.

Lei de Diretrizes e Bases da Educação Nacional. Lei n 9.394, de 20 de dezembro de 1996. Estabelece as diretrizes e bases da educação nacional. Brasília, DF, 1996.

CORRÊA, E. J. Extensão universitária, política institucional e inclusão social. Revista Brasileira de Extensão Universitária, Chapecó, v. 1, n. 1, p. 12-15, 2003.

CUMMINGS, W. K. The service university movement in the US: searching for momentum. Higher Education, Amsterdan, v. 35, n. 1, p. 69-90, 1998.

CONTO, F. de A extensão universitária na Faculdade de Odontologia. Em Extensão, Uberlândia, v. 12, n. 2, p. 100-108, jul-dez. 2013. 
DE PAULA, J. A. A extensão universitária: história, conceito e propostas. Interfaces, Belo Horizonte, v. 1, n. 1, p. 5-23, jul.-nov. 2013.

DEGREAS, H. N.; KATAKURA, P. Prática experimental em ambiente acadêmico: relato de experiência desenvolvida no escritório-modelo do curso de Arquitetura e Urbanismo do FIAM-FAAM Centro Universitário. Extensão em Foco, Curitiba, n. 3, p. 173-181, jan.-jul. 2009.

DIOGO, M. J. D’E. Formação de recursos humanos na área da saúde do idoso. Revista Latino-americana de Enfermagem, Ribeirão Preto, v. 12, n. 2, p. 280-282, mar./ abr. 2004.

FONSECA, M. C. F. R. et al. O significado de um projeto de extensão universitária na formação inicial de educadores de jovens e adultos. In: REUNIÃO ANUAL DA ANPED, 23., 2000, Caxambu. Anais... Belo Horizonte: ANPED, 2000. 1 CD-ROM.

FORPROEX - Fórum dos Pró-reitores de Extensão das Universidades Públicas Brasileiras. 1987. Disponível em: <http://www.renex.org.br/documentos/Encontro-Nacional/1987-IEncontro-Nacional-do-FORPROEX.pdf > Acesso em: 4 fev. 2014.

FREIRE, P. Extensão ou comunicação? Rio de Janeiro: Paz e Terra, 1997. (Publicado originalmente em 1969, no Chile, sob o título ¿Extensión o comunicación?).

GERHARDT, V. A ideia de Humboldt sobre a atualidade do programa de Wilhelm Von Humboldt. In: ROHDEN, V. (Org.) Ideias de universidade. Canoas: Editora da ULBRA, 2002.

GILES, D. E.; EYLER J. The impact of a college community service laboratory on students' personal, social, and cognitive outcomes. Journal of Adolescence, Amsterdan, v. 17, p. 327 329, Aug. 1994.

GUTIÉRREZ, O. A. Consideraciones en torno al concepto de extensión de la cultura y los servicios. Revista de la Educación Superior, Benito Juarez, v. 81, p. 53-69, 1992.

LAURSEN, S. L.; THIRY, H.; LISTON, C. S. The impact of a university-based school science outreach program on graduate student participants' career paths and professional socialization. Journal of Higher Education Outreach and Engagement, Athens, v. 16, n. 2, p. 47-78, 2012.

LICHTENSTEIN, G. et al. Development of a national survey to assess student learning outcomes of community-based research. Journal of Higher Education Outreach and Engagement, Athens, v. 15, n. 2, p. 7-33, 2011.

LYNTON, E. Reexamining the role of the university. Change, Philadelphia, v. 53, p. 19-23, 1983.

MATTHEWS, P. H. Developing and evaluating a student scholars program to engage students with the university's public service and outreach mission. Journal of Higher Education Outreach and Engagement, Athens, v. 16, n. 4, p. 165-179, 2012.

MLODINOW, L. Subliminar: como o inconsciente influencia nossas vidas. Rio de Janeiro: Zahar, 2013. 
MOELY, B.; FURCO, A.; REED, J. charity and social change: the impact of individual preferences on service- learning outcomes. Michigan Journal of Community Service Learning, Ann Arbor, v. 15, n. 1, p. 37-48, 2008.

MUSCIO, C. Exit surveying of interns: demonstrating impact on young professionals. Journal of Extension, Columbus, v. 49, n. 3, 2011.

OSBORNE, R. E.; HAMMERICH, S.; HENSLEY, C. Student effects of service-learning: tracking change across a semester. Michigan Journal of Community Service Learning, Ann Arbor, v. 5, n.1, p. 5-13, 1998.

PHELPS, A. M.; DOSTILIO, L. Studying student benefits of assigning a service-Learning project compared to a traditional final project in a Business Statistics Class. Journal of Statistics Education, v. 16, n. 3, 2008.

PONTE, C. I. R. V. et al. A extensão universitária na FAMED/UFRGS: cenário de formação profissional. Revista Brasileira de Educação Médica, Rio de Janeiro, v. 33, n. 4, p. 527$534,2009$.

REED, V. A. et al. Effects of a small-scale, very short-term service-learning experience on college students. Journal of Adolescence, Amsterdan, v. 28, p. 359-368, 2005.

ROGERS, B.; MASON, K.; CORNELIUS, J. Involving undergraduate students as extension program interns. Journal of Extension, v. 39, n. 5, Oct. 2001.

ROMACK, J. L. Is service learning making the grade? Academic Exchange Quarterly, New York, v. 7, n. 2, 126-129, 2003.

ROPER, C. D.; HIRTH, M. A. A history of change in the third mission of higher education: the evolution of one-way service to interactive engagement. Journal of Higher Education Outreach and Engagement, Athens, v. 10, n. 3, p. 3-21, 2005.

SANTOS, A. B. et al. Extensão universitária: a visão de acadêmicos da Universidade do Estado de Santa Catarina (UDESC). Em Extensão, Uberlândia, v. 12, n. 2, p. 9-22, jul.-dez. 2013.

SCOTT, J. C. The mission of the university: medieval to postmodern transformations. The Journal of Higher Education, Las Vegas, v. 77, n. 1, p. 1-39, 2006.

SEIDER, S. C.; GILLMOR, S.; RABINOWICZ, S. The impact of community service learning upon the expected political voice of participating College students. Journal of Adolescent Research, Amsterdan, v. 27, n. 1, p. 44-77, 2012.

SEIFERT, P. A. Newman sobre a universidade. In: ROHDEN, V. (Org.). Ideias de universidade. Canoas: Editora da ULBRA, 2002, p. 93-103.

SEVIER, C. et al. What value does service learning have on introductory engineering students' motivation and abet program outcomes? Journal of STEM Education: Innovations \& Research, Auburn, v. 13, n. 4, p. 55-70, 2012.

SIMONS, L.; CLEARLY, B. The influence of service learning on students' personal and social development. College Teaching, Oxford, v. 54, n. 4, p. 307-319, 2006. 
SIMPSON, G. Extension is not just service, but service learning is important to extension. Journal of Extension, v. 36, n. 5, 1998.

SOUSA, A. L. A história da extensão universitária. Campinas: Alínea Editora, 2010.

SOUSA SANTOS, B. Universidade no século XXI: para uma reforma democrática e emancipatória da Universidade. 3 ed. São Paulo: Cortez, 2010.

UDELAR - Universidad de la República de Uruguay. Hacia la reforma universitaria: la Extensión en la renovación de la enseñanza: espacios de formación integral. Montevideo: UDELAR, 2010.

VOGELGESANG, L. J.; ASTIN, A. W. Comparing the effects of community service and service-learning. Michigan Journal of Community Service Learning, Ann Arbor, v. 7, n1, p. 25-34, 2000.

WEILER, L. et al. Benefits derived by college students from mentoring at-risk youth in a service-learning course. American Journal of Community Psychology, v. 52, p. 236-248, 2013.

ZIEREN, G. R.; STODDARD, P. H. The historical origins of service-learning in the nineteenth and twentieth centuries: the transplanted and indigenous traditions. In: SPECK, B. W.; HOPPE, S. L. (Ed.). Service-learning: history, theory, and issues. Westport: Greenwood Publishing Group, 2004.

Submetido em 29 de maio de 2014.

Aprovado em 4 de Agosto de 2014. 